\title{
Information in Plant Life and Development: A Biosemiotic Approach
}

\author{
Peter W. Barlow
}

School of Biological Sciences

University of Bristol

Woodland Road

Bristol BS8 1UG, UK

P.W.Barlow@bristol.ac.uk

\begin{abstract}
Plant cells, organs and organisms develop via a succession of transformations of their state mediated by the prevailing systems of metabolism and morphology. These transformations are facilitated by the perception of, and response to signs and signals generated either from within, or received from an external source - the abiotic environment, for example. The perception of signs and their subsequent transformation and integration in the form of plant-specific information, may depend upon a channel which has features of a 'nervous' system and which employs some of the molecular components and organelles familiar in animals. Developmental transformations can also be described in symbolic form by means of L-system algorithms (after A. Lindenmayer) whose elements have counterparts corresponding to the boundaries of cells and multicellular societies. The cell maps resulting from these algorithms enable retrospective inferences and future predictions about the behaviour of the cellular systems con-
\end{abstract}

cerned. L-systems therefore offer a means of encapsulating the elements of the 'living algorithms' which may be supposed to be already embedded within an organism and which are responsive to signs which are an integral part of the already formed construction. Another class of sign system in plants is suggested as being based on gradients of biochemical agents, or morphogens, which promote cell determination and hence lead to distinctive patterns of tissue differentiation.

Keywords: autoreproduction, development, information and communication, L-systems, plant meristems

Acknowledgement: I am grateful to Günther Witzany for introducing me to Biosemiotics, and also there are special thanks to my colleagues František Baluška and Jacqueline Lück for their continually inspiring insights relating to the world of plants.

\section{Introduction. Biosemiotics in the New Age}

Can it be said of European Man that he has successfully passed through not only an 'Age of Reason' illumined by the Enlightenment (Porter 2000) but also an 'Age of Anxiety' fostered by two world wars (Valéry 1919, Auden 1947), and that he is now squarely settled in an 'Age of Communication' (Chan 2005)? Or has European Man not made any passage at all, but has, instead, simply gathered to himself, like a rolling snowball, the ethos of each of these ages (White 1944)? The persistence of myths and the belief in eternal archetypes suggests that the latter proposition is more likely. Whatever the case, it is an everyday experience for men and women to believe themselves deluged, if not suffocated, by a mass of information from which items crucial for everyday living as well as for long-term decisions have nevertheless to be extracted. It is not surprising, therefore, that the study of signs and communication - semiotics has become a rapidly expanding field of enquiry (Hawkes 1989, Witzany 2006) not only for its own sake but also to understand and cope with the pathologies that attend the reception of distorted or conflicting information. And, moreover, the contact in this field of signs with biologists - behaviourists at first, but later 
with molecular biologists also - inevitably has led to the conception and birth of Biosemiotics. However, whether this new offspring now growing up within the world of Academia will manufacture anything more than new bottles within which to store old wines remains to be seen. Hopefully, this will prove not to be the case, and that biosemiotics will stimulate coherent concepts from which the varied modes of inter- and intra-organismic communication can be formulated with a new scientific rigour.

At much the same time as developments in an area which had originally been oriented towards studies of verbal and linguistic interactions were leading towards structuralism and semiotics (Piaget 1971, Hawkes 1989), there was a similar surge of interest in how interrelationships between the multiplicity of processes, informational and otherwise, which were increasingly discernable within the living world, could be interpreted and, better still, harmonized with analogous processes recognized within those scientific disciplines which dealt with inanimate matter. Perhaps the fundamental disquiet which lay behind this search for logical connections was the two-fold legacy from the Ages of 'Reason' and 'Anxiety'. Nevertheless, from this striving for an ideal representation of nature and her laws arose the General Systems Theory of Ludwig von Bertalanffy (1950), an important off-shoot of which was Living Systems Theory (LST). Developed by James Grier Miller in the 1960s, and later in collaboration with his wife, Jessie Louise Miller, LST recognised a coherent set of integrative processes, or subsystems, which were similar in character over the span of all conceivable levels of biological organization (JG Miller 1978, JG and JL Miller 1990). These subsystems were postulated to support and to define each of the organizational levels considered by LST. There are three principal groups of subsystems, one of which is exclusively dedicated to the processing of Information. The other two groups of subsystems pertain to the processing of Matter and Energy-plus-Information. Together, the three subsystem groups cohere and thereby permit the realization of the three major attributes of living matter namely, reproduction, metabolism and acquisition of structure. The levels of organization which the sets of subsystems support, and are supported by - there is here a reciprocity of functions! - range from cells, through organs and organisms, to social groupings. Whereas JG Miller conceived of eight hierarchical levels of organization for Man and his society (Miller 1978) - an ninth level, that of Gaia, was later added to this list (Miller and Miller 1982) - the first three mentioned here (cells, organs, organisms) are sufficient for the present short discussion of information in plant life and plant development.

\section{Information and Living Systems}

Central among the information-processing subsystems of LST are those which concern sign perception, transduction, and the transmission of the resulting encoded version of the sign (information) via a 'channel and net' subsystem to a site at which the informational signal is decoded and a response (usually a motor or tropic response of some description) evoked (Barlow 2007). However, the existence of such a sequence of information-processing has already been known to plant physiologists for many years (Jackson and Barlow 1981, Mohr and Schopfer 1995), as was a 'systems' approach to studying the plant organism; remarkably, this latter had been adopted nearly 125 years ago by Gottlieb Haberlandt and expounded in his book 'Physiologische Pflanzenanatomie' ('Physiological Plant Anatomy') (Haberlandt 1884). The structural and functional attributes of the subsystems of LST has required many man-hours of research to become more clearly identified and better understood. In plants, it has until recently been difficult to find correspondences between the various information-handling subsystems proposed by LST and actual anatomical structures and physiological processes (Barlow 1999, 2006, 2007). In particular, the 'channel and net' subsystem of LST, which deals with information flow, existed hitherto largely as a theoretical supposition based on analogy with information-processing subsystems in sensate animal organisms. However, the advent of the new science of plant neurobiology (Brenner et al. 2006) has provided valuable pointers to the sought-after correspondences between predicted and actual structures concerned with information flow, as well as indicating anatomical and cell-biological frameworks within which the said structures can be integrated. Therefore, there is the prospect that, in the near future, a more complete plant informationprocessing system will be revealed (Baluška et al. 2006, 2007, Barlow 2007). Unfortunately, there has 
been some misinterpretation (Alpi et al. 2007) concerning the concept of plant neurobiology, and the goals which have been set for this discipline. Plants are not animals, even though both may have channel and net subsystems for the conveyance of information in one form or another. This 'channel and net' subsystem is approximately analogous to an anatomically identifiable 'nervous system'. In fact, LST provides an objective framework for a study such as plant neurobiology (Barlow 2007) because not only is the subsystem terminology self-sufficient and precisely defined but so also are the subsystem functions (Miller 1978, Miller and Miller 1995). There is no particular necessity to search out the correspondences with anatomy, though for practical purposes this is clearly desirable (Miller 1978). The argumentation can work in reverse, however, so that terms like 'nerve' and 'nervous system' become, in the objective terminology of LST, metaphors for 'channel and net' at two corresponding organizational levels. 'Nerve' can even become a generalised metaphor applied within the community of life-forms, irrespective of whether these are also designated 'animal' or 'plants'.

The processing of information by a living organism involves a relationship between the physical variables of which the organism's external, abiotic environment is comprised, and the specialized biological receptors which respond to them. Obviously, some heterogeneity within the environment becomes identifiable as a 'signal' only when it invokes recognition and a subsequent response from an organism. Many relevant examples of signals have been investigated in plants, most of which culminate, via signal transduction into internal information, and thence to end-point responses (Barlow 1992). These end points include the specialized growth movements (tropisms) which become evident as a result of displacements of organs (roots, shoots) in relation to the gravity vector (gravitropism), gradients of illumination (phototropism) and other environmental variables such as temperature, oxygen levels, etc. (Jackson and Barlow 1981, Mohr and Schopfer 1995, Porterfield 2002). These causative agents of movement are the environmental heterogeneities mentioned earlier. Interestingly, in plant roots, it has recently been discovered that particular groups of specialised cells (e.g., those in the centre of the root cap) can process two or more streams of information simultaneously - e.g., those due to stimuli from gravity, light, and also humidity (Takahashi et al. 2003). At some stage, this processing leads to associations and decisions (both governed by two other LST subsystems) as to which motor response is the most appropriate in the prevailing circumstances - the root movements of gravitropism, phototropism, or hydrotropism.

The sensing and integration of stimuli, or signs, may be placed under the two broad headings of exteroception and interoception (Barlow 2007). The former term covers the reception of the above-mentioned external signs, while the latter, interoception, includes the sensation and response to internal signs and signals. Both types of signal reception relate to the particular morphological configuration, or orientation, of an entity of a certain level within its living-space. Also worth recalling is the observation that plants, as well as animals, are unable to tolerate constant conditions (a situation of 'sensory deprivation') (Hillman 1956, Highkin 1960). Constancy of ambient temperature, for example, leads to the reproductive death of pea plants (Highkin 1958). It is as though continual variation in the intensity of stimulation is what organisms crave in order to maintain not only the physical structure of the subsystems but also their integrated and healthy state.

Plants seem to have exquisite sensitivities to certain types of environmental signals, often at extremely low, near-threshold levels of detection, and have the means of capturing them and converting some signrelated physical or chemical feature into information which can then be amplified and processed by the subsystems, and passed between different organizational levels (Barlow 2007). However, the relevant systems of perception and response also have upper thresholds in relation to the abiotic environment (Went 1956, Barlow and Powers 2005). It is likely that these upper limits are related to the malfunction and collapse of the physiological processes involved. Moreover, it is important not to forget that within the responsive zone between upper and lower thresholds a given perceptive system is ever-active, just as the stimulus, or sign, is ever-present. Beyond the limits of this zone, sign perception and/or transduction would 
be inactive; and this absence of activity, too, might be perceived in some circumstances as an internal signaling state, perhaps residing as a 'memory' of unfavourable growth conditions (the memory becoming retrievable when the environment ameliorates and growth resumes). However, within the perceptive zone between lower and upper thresholds there are states of continual interoception which are registered as a form of self-consciousness which also can be referred to as a state of 'continual semiosis' (Barlow and Lück 2007a). It is interesting to speculate that Charles Darwin would have recognized continual semiosis in consequence of his detailed observations of the intrinsically driven nutational movements of plant stems and tendrils (Darwin 1880). For him, these organs seemed to be perpetually in search of stimuli (a selfdirected desire for the reciprocities of semiosis?) in order to initiate new modes of growth - twining and other motions - for raising up the plant body.

\section{$3 \quad$ Novel Forms of Information Processing}

Perceptions at the lower threshold of a sensory system may be so weak that the information engendered has little impact beyond its immediate site of susception and processing. The information remains at the level (say, of the cell) at which it was first registered or processed, and does not become amplified and move up to the next higher organizational level where it can be registered by the whole organism as some type of physiological 'shock' or disturbance from which a high-level response is engendered (bodily motion, for example). Such 'low level', or prototypic, feelings and sensations, internalized at the level at which the initiating signals were perceived, thus give rise to what are spoken of (for animal forms, at least) as intuitions and telepathies. It is suggested that, in plants, these same prototypic feelings are just those which have been termed 'primary perceptions' (Backster 2003). Therefore, the 'continual semiosis' mentioned above may not only be converted into satisfying and gratifying sensations of a high-level self - i.e., as an organism either afflicted by pain or suffused with pleasure, or into sensations which goads the organism into motor activity - but this proposed autosemiosis (like a type of proprioception) also results in subliminal sensations of which the organism is only vaguely aware. Primary perception may perhaps play a relatively more significant part in plant life than it does in animals, especially humans. Plants often have to rely on weak and ephemeral signals from the ambient environment for their self-maintenance and reproduction. At levels 'lower' than that of the whole organism (i.e. cell and organ levels), such feeble signals are experienced by correspondingly 'low-level' subsystems, and that these can set in motion only a train of instinctive responses: there is no transmission to, or integration of the relevant information with and higher organizational level.

Complementary to the systems which participate in exteroception, or the outer-to-inner capture of signals from the external environment to the interior of the plant and their conversion into information, are the many examples of organismic components responding to interoception - that is, to their own innatelygenerated information resident within the internal biotic environment. This last-mentioned environment, as we might now anticipate in accordance with the principles of nested hierarchical levels of LST, ranges from the components of the cellular level to the more fully realized entities at the levels of the community and its ecological setting. Moreover, what might be observed as 'outer' at one level (e.g., fungal hyphae are 'outer' in relation to the surface of a root) becomes 'inner' at a higher level (e.g., hyphae and root become part of a composite mycorrhiza within a rhizosphere). However, it is behaviour at the cellular level which informs our further discussion of the responses to internal informational signals in relation to biological development.

Interestingly, the nesting of hierarchical levels elucidates the concept of 'emergent properties', a puzzling phenomenon that is, nevertheless, part and parcel of development. For example, it is cells which give rise to the novelty of a tissue; and, at a different level, it is the physical conjunction of two organisms as a 'dyad' which gives rise to a new life-form. Familiar examples of dyads, besides the mycorrhizae already mentioned, are lichens (Sanders 2006). These are constructions which arise from the conjunction of algal and fungal organisms. Importantly, by their association, the resulting lichen-dyad is rendered repro- 
ductive, a property denied to the two independent component parts. Similarly, the pairing of animals and plants by means of their male and female genders brings about another type of reproductively competent dyad (Barlow 1999).

\section{Development and Morphogenesis}

A beautiful image is that of the penetrative plant or animal sperm informing the egg that a new organism should now be constructed. But after this initial acceptance of external seminal information, development is prompted by internal cues generated by the new organism itself. It is a feature of plants that their construction is based on the principle of the module (Notov 2005). Development is therefore by repetitious production of modules. And new modules arise by autoreproduction (Barlow et al. 2001; see also Wagner 1996).

A succession of reasonably well-defined states, or forms peculiar to a certain chronological stage of development, are recognisable as organismic growth proceeds, this process being promoted by two of the attributes of living organisation - metabolism and the acquisition of structure. The former depends upon the acquisition of substrates and energy sources, the latter upon the inherent properties of self-assembly and autoreproduction. In the very simplicity of a zygote, at the commencement of each new generation, organisms have a form, and this form will be continually repeated in accordance with the condition (or constaint) of modularity. The zygotic form, it seems, is one condition necessary to advance, or transform, development to the next state. Admittedly, the steps of early embryogeny are relatively simple: the progression of $2,4,8,16, \ldots$ cells is accompanied by a parallel sequence of embryonic stages - 'globule', 'heart', and 'torpedo'. The important point is that there seems to be an inevitability about these progressions. In insect and animal embryos, these have been linked to the hypothesis of the 'zootype' whereby the linear sequence of a number of homeobox genes co-locates with the body plan of the embryo (Slack et al. 1993, Deutsch 2004). It is possible that some similar morphogenetic concept may apply to plant embryogeny also (e.g. Paquette and Benfey 2001, Jürgens 2003).

Evidently, an appropriate metabolism and a set of active genes not only maintain the supply of elements necessary for development but they also set the rate at which this occurs. Then, structure and metabolism combine to define the species-specific rates of both cell growth and cell division. In their turn, these parameters affect cellular polarity and geometry, realms wherein operate rules which regulate the siting of each new cell division wall within a cytokinetic mother cell (Gönczy and Hyman 1996, Barlow et al. 2004a, Pillitteri et al. 2007). This coordinated sequence of cellular events hints at a type of development whereby the state of a construction at a given timestep predicts, as a result of information contained within that construction, the precise state that will emerge at the following timestep. Given the selfsimilarity within the organizational hierarchy, this same principle should apply at each level of organization: cell, organ, organism, and even at the level of a social group. Importantly, the transition from one state to another is neither spontaneous nor chaotic, but is directed; it is facilitated by the perception of, and the response to, a sign (or signs) inherent to the construction in its current state. This principle is at the heart of organic autopoiesis (Varela et al. 1974) and autoreproduction (Barlow et al. 2001); and inherently communicative signs may be found in the labile molecules of the plant cell wall (Nothnagel 1997). But, in order for these events to occur, the system itself must be in the already mentioned state of self-sensing, or continual autosemiosis. Signals already within the existing construction, some of which, in the case of mobile plant hormones (Gazzarrini and McCourt 2003), participate in quite complex configurations, have to impinge upon some matching perceptive system. From the nexus of signals, information and responses, another level of organization manifests (an emergent property), via a chain of information processing, not only to realise the Bauplan of the organism but also to accommodate small variations upon its theme in the form of tropisms of organs, liminal angles of branches, morphological adaptations, plasticities of development, etc. (Barlow 1993, Walbot 1996). 
In order to further the argument for directed development, and to relate structure and form with semiosis, the principal element in plant organogenesis will be taken to be the individual cell. Except for gametic cells and in-vitro cultured somatic cells which have been released from the constraints of their neighbours, plant cells are usually seamlessly joined together in three-dimensionally constructed societies (or 'cellworks') where not only are their developmental potentialities regulated in ways appropriate to cellular position within an organ, but also the boundary walls of cells exhibit non-random spatial arrangements and states of maturation, all of which may serve as signs and signaling systems. It seems that the intimate contact of cell upon cell (and any one cell usually has about 14 or more contacts with neighbouring cells) and the exchange of information therefrom, are crucial in the generation of form. It is at the growing points of plants - the apices and apical meristems - where cellworks and their signaling systems display their most intriguing properties (Lück and Lück 2000). During steady-state plant growth an ever-changing cell population maintains a constancy of behaviour out of which shape and form are developed in accordance with the mysterious processes of morphogenesis. The familiar hooked shape of seedling plumules, for example, is maintained even though the cells from which the plumules are constructed are continually being exchanged for new cells derived from the shoot apex (Silk and Erickson 1978). But besides this constancy of form ${ }^{1}$, there are resident within root and shoot apices generative centres which consist of self-maintaining stem-cells and their immediate descendents. The generative centres may then proceed to develop the germs of new centres from which new organs arise by a branching process (Barlow et al. 2001, Barlow and Lück 2004a, Barlow et al. 2004b). As mentioned, this process of autoreproduction is characteristic of living modular constructions.

Can the signals which drive forward the transformations characteristic of plant development be described in such a way that the symbols employed for its representation would make sense if presented (in a suitable language, of course) not only to an individual cell and the cellular society which houses it and grows up from it, but also to a biologist who might study them? Or, put another way, can algorithms for development be discovered whose symbolic elements have, on the one hand, counterparts within the respective constructions themselves (i.e., could there be cell-based 'living algorithms'?) and which can be recognized as signals for development, as well as being able to convey to an external observer enough information for him to infer past and present patterns of development as well as predict its future course? We shall now try to answer this question.

\section{$5 \quad$ Structuralism and L-systems}

While semiotics and biosemiotics have many correspondences with the discipline of structuralism, and together they have become combined within a discipline of 'communication' (Hawkes 1989), structuralism itself came more clearly into focus, as Jean Piaget discovered, by contact with advances in the analysis and understanding of the biological world (Piaget 1971). It may also be ventured that the focus of structuralism was further sharpened in the light of General Systems Theory, as well as from insights gained through the development of L-systems (Lindenmayer 1971). These last-mentioned systems (due to Aristid Lindenmayer - hence the ' $L$ ' of 'L-systems') offer one possible means of representing the soi-disant 'living algorithm', conceived of as being embedded within the very structure of the organism itself and which offer signs whose interpretation furthers development.

Because it is of interest to explore the extent to which a single cell (though not one isolated from neighbouring cells) can reproduce, and by its productions develop a society of similarly reproducing cells from which various subsidiary patterns of activity can come about, minimal interactionless algorithms have been devised (Barlow et al. 2001, Barlow and Lück 2004a). These are of the DOL-system type (Lück and

\footnotetext{
${ }^{1}$ As Heraclitus wisely observed nearly three millennia ago, "You never step into the same river twice, as fresh water is always flowing towards you." So it is for the cells of the plumular hook.
} 
Lück 1987), where $D$ indicates deterministic, 0 designates the absence of interactions, and $L$ is as mentioned above.

DOL-system algorithms are transformation rules which employ a triadic form of symbolism, for example, $A \rightarrow B$, or $B \rightarrow B$. In the first case, the A state evidently has the potential to transform to the $B$ state. The $A$ state may even be considered as exhibiting 'biosemiotic readiness' - continual semiosis - anticipating a change of state upon completion of a timestep, as implied by the transformation symbol ' $\rightarrow$ '. The arrow also suggests that there might be a direction to development. Due to its biosemiotic readiness, the $A$ state cell has the potential to make a forward movement and thereby attain state $B$. In the second case, the transformation B $\rightarrow$ B is likewise indicative of continual semiosis: before the conclusion of a timestep, when rule-governed state transformations are implemented simultaneously throughout the cell population, each B-type cell actively assesses, within the context of its semiotic environment (or 'semiosphere'), whether to remain in $B$ state or not. In the case of $B \rightarrow B$, however, the state is unchanged, indicating that the sensitive components of $B$ which are active in continual semiosis have not encountered sufficient information to secure a transformation to some other, non-B, state. Some threshold has not been crossed. Thus, as long as such a semiotic environment persists, cell-type B will appear to be a terminal state. Nevertheless, the cell's self-maintenance in B state might be challenged by, say, a pathogenic infection, or a wound, in which case further state transformations, e.g. B $\rightarrow$ D or B $\rightarrow A$, could be facilitated. The B cell may not, therefore, be so terminal after all, and may even have the ability to marshall the conditions in the surrounding semiosphere so that they lead to its own death via apoptosis (say, state D). Can any state therefore ever be considered as final? Continual semiosis would suggest a condition of 'continual becoming', even if this requires the occasional return to the initial state $(B \rightarrow A)$.

L-systems, as sequences of state transformations, thus prove useful simulators of morphological change in plants and algae (Lindenmayer 1971, Lück and Lück 1987). In circumstances where state transformations operate at the edges of cells, cellular maps are the preferred means of graphically representing the progressively altering form of the resultant cellular arrays (Lück and Lück 2000, Barlow et al. 2001, Barlow and Lück 2004a, 2007a). Each edge may correspond to a wall, or to a segment of wall, accompanied by its underlying cytoplasm; and each state of a wall may be defined by some time-dependent property. Transformation of state implies a preceding phase during which information required for this transformation becomes active as a signal. Thus, the states that correspond to the make-up of the wall (say) are not informational per se; they become informational and, hence, contribute the 'living' counterparts of an L-system algorithm, only when there is a higher level of organization within which they are interpreted following their interoception. To paraphrase $\mathrm{H}$. Pattee in relation to the cell edges mentioned above, 'an edge does not become a message because of any shape or structure or behavior of the edge. It becomes a message only in the context of a larger system of physical constraints' (Pattee 1969). In the case of the 'living algorithm', this 'larger system' of constraints is the cell division system. It should not be forgotten that L-systems also apply to the transformations of cellular states (Barlow and Lück 2004a). These states are elements resident in a higher level of organization (that of the organ) than that in which the edge resides (at the level of the cell). In both cases, edge state and cell state are signs, but they feature at different levels.

Extending the algorithmic terminology to that of a double-wall $(\mathrm{dw}) \mathrm{L}$-system permits the state of one wall to be considered in relation to the state of a connected wall belonging to a neighbouring cell (Lück and Lück 1987). It can be imagined that both walls are attached to a common, but invisible, membrane (hence the idea of the double wall and the corresponding labeling of each of the two faces). Thus, cellular groups, whether in 1, 2, and 3 dimensions - filaments, arrays, and cellworks, respectively - are linked by a set of symbols that refers to the states of the connected cell edges. Suitable transformation rules then allow the cellular ensembles to coordinate their development in time and space (Lück and Lück 2000). No exchange of information between cells takes place, however. In fact, a number of developing cellular sys- 
tems (plant and algal idioblasts) were recently proposed (Barlow and Lück 2007b) to arise on account of a cessation of information flow. Again, a particular type of wall state transformations was invoked as the agent of cellular change.

Examples of the usefulness of L-systems not only in the analysis of cellular autoreproduction at the generative centres of a shoot of the whisk-fern, Psilotum nudum, but also in showing how variations upon their self-maintaining, autoreproductive condition lead to cellular differentiation, have been set forth elsewhere (Barlow et al. 2001, 2004b, Barlow and Lück 2004a, 2007a). In all cases described, the cellular activities derived from an algorithm that commenced with a 3-sided cell and a wall cycle, denoted as (1 2 $3)$. The state transformation rules then led to a developmental map. In the case of unrestricted development of the theoretical cell division system for the Psilotum apex, the real-life counterpart in real life would be a succession of dichotomous branchings expressed as clusters of telomes, terminal structures arrived at during evolution for gaining a competitive advantage (overtopping) over neighbouring plants and their telomes ${ }^{2}$. However, actual Psilotum apices achieve only about 16 branches. In the algorithm for apical development, the limit to branching is set by a cell division counter referred to as $\lambda$, but how this counter operates is not known; there could be some feedback between old cells (those produced $\lambda$ generations ago) and the stem-cell population at the apex, or there may be more subtle ways of limiting proliferation, such as by the progressive loss of telomeres - these are special sequences of DNA bases associated with the ends of chromosomes (McKnight 2004) - at each division step in the initial cell population.

The deterministic DOL-system algorithm of unlimited development produces an 'ideal', or 'stereotypic', cellular pattern. But whereas complex and invariant cellular constructions obviously do arise, and without them there could be no consistent morphology for a given plant species, inherent disturbances (chance events?) to the otherwise stereotypic division system can serve to bring about new pathways of cell behaviour and differentiation.

Whatever the explanation for the 'accidental' divergence of division pathways, the continual semiosis operating within 3-sided cells provides a suitable vehicle for evolutionary selection. The induction of variants of a given developmental pathway as a response to disturbed external or internal conditions, can become fixed as a result of genetic assimilation. In this way, new patterns of cellular development and morphogenesis arise (which in terms of the alphabet of L-system symbols may involve only small changes), and with them the formation of new species (see Morelli et al. 1991).

\section{Cellular context as semiotic signal}

In relation to the semiotics of morphogenesis, a further consideration is the context within which the cell division systems for cellular autoreproduction and differentiation are embedded. As discussed elsewhere (Barlow and Lück 2007a), the cycle of wall edges provides not only a set of semiotic signs, but also the semiotic context for sequences of cell division and the development of different cell types which diverge in their properties.

Another instance of context was recently proposed in an attempt to understand the recurrent patterning of the secondary phloem tissue of coniferous and deciduous trees in relation to the behaviour of the vascular cambium from which this tissue derives (Barlow and Lück 2004b, 2005, 2006). In this case, the theoretical context was a radial gradient across the tissue of a putative chemical morphogen whose source was in the cambium (Kramer 2001). The gradient constitutes a signal and forms an integral part of a model whereby uncommitted meristematic cambial cells are guided towards particular pathways of differentiation as they move centrifugally across the secondary phloem domain. Particularly gratifying was the realization that these putative gradient-directed developments within a plant tissue were similar to those

\footnotetext{
${ }^{2}$ This overtopping characteristic of telomes is like that of the four-wheel-drive 'people-carrier' automobiles where new models continually overtop not only the more modest family saloon-type cars but also the older models of their own type (as was the case with successive species of dinosaurs)!
} 
discovered, or inferred, in animal systems (gradients of morphogens regulating segmentation in vertebrate embryos, for example) (summarized in Barlow and Lück 2004b, 2005). Moreover, since gradients of metabolites abound in plants (van Fleet 1948), it would not be surprising if they, too, conferred positional information for use in cell determination and differentiation. The other key component of the secondary phloem system is the spatio-temporal pattern of periclinal cell divisions in the cambium. In correspondence with the examples from Psilotum, a given division system may arise from deterministic transformations of a particular cambial cell wall cycle. Because of the geometric complexity of cambial anatomy (Barlow 2005), the potential for the presence of signs inherent to the configurations of the cell walls and the respective cell contacts is likely to be high.

\section{Evolution of an L-system-based semiosis}

Within the present context of Biosemiotics, it seems appropriate to speculate upon the evolution of the plant meristem's 'living algorithms' of which L-systems are the symbolic representations. It may be presumed that, as one of the first steps in plant evolution, the apical type of meristem superceded meristems of both the intercalary and the diffuse types. In contrast to the two last-mentioned types, the apical type of meristem is a site where more possibilities for the regulation of morphogenesis can be tried out. But in order for any one of all the possible division pathways to become established and acquire relevance for cellular differentiation and for organ development, many experiments must have been made during the vast expanse of evolutionary time. Division pathways that were either abortive or stable in terms of the output of cell patterns would have been trials to find those which were productive of an emergent property. As witness to this, it has been found (Bugnicourt 1983) that during the embryogeny of certain French species of Hypericum even the smallest errors of cell division lead to the death of the embryo. It is as though, at this critical stage, the self-assembly of information for developmental progress has to be unswervingly precise in relation to the whole, otherwise the growing system will be aborted. At length, however, living algorithms would have been selected, and they would have been the ones to communicate sufficient information, via self-organising structures, to forge robust division pathways that then led to repeated branching and modularity of shoot and root apex (Barlow et al., 2004b). Thus, during this experimental era early in plant evolution, not only was it necessary for the structure of walls to be such that cells could divide in particular planes, but that the resulting cellular patterns could generate viable organ-forms, and that these forms in their turn could cohabit with other similar organ-forms, and then with the life-forms of other species.

The L-system algorithms derived for plant constructions suggest an analogy with the vocal language of animals, especially primates and hominids, even though with respect to each type of construction quite different levels of organization are involved. Here, the selection of a living plant algorithm could have proceeded in much the same way whereby the continuous vocalizations of primitive hominids coalesced into particular sound clusters, again after an experimental stage, which established the consensual phonemes by which groups of individuals could collectively begin to name objects, communicate ideas, and thence to cooperate in the construction of societies (Novak and Krakauer 1999, Kirby 2001, Walsingham 2006). That phonemes can be considered as 'consensual' implies that a sufficient number of individuals of equivalent intellectual development exists during this period of linguistic experimentation; these individuals, then, are the context in which the phonemes are cognized.

The respective algorithms or phoneme clusters became the means whereby the entities to which they belong - cells or individual organisms - were diverted from self-sufficient solitude and acquired companionable neighbours with whom they may have been able to communicate. But at the same time, the newly developed ability of hominids living in this 'Age of Palaeolithic Reason' to differentiate 'this' from 'that' led, paradoxically, to an 'Age of Prehistoric Anxiety' where there was a sense in each individual of a separation, or an apartness, from the matrix of their natural environment. The development of a continual semio- 
sis, of a self-awareness and environmental consciousness, would certainly have been one way (maybe the only way) in which contact within and between organisms, animal or plant, as well as the organisms' contact with the environmental continuum of which they themselves were also a part (the 'Umwelt' of J.J. von Uexküll), could have been maintained, and the primordial 'anxiety' assuaged. However, as indicated, there may be another, more prototypical way of sensing via primary perception. But this, perhaps, is a research area not yet within the reach of Biosemiotics and communication studies for the foreseeable future.

\section{Conclusion}

Plants grow and develop in accordance with information gained from external and internal signals which are captured by the processes of exteroception and interoception, respectively. The passage of information, and the subsequent activation of a response, can be understood in the framework of J.G. Miller's 'Living Systems Theory' (LST). There is increasing evidence for the existence in plants of a type of nervous system which includes synaptic structures. Its counterpart in LST is the 'channel and net' proposed as being one of the subsystems involved in information transfer.

With respect to plant cell division and the building of cellular constructions, Lindenmayer-systems have provided useful algorithms for modelling the steps involved. The symbolic forms of the L-system algorithms presumably have counterparts within the organism itself, perhaps associated with the cell walls and underlying cytoplasmic structures. Their changing states can be sensed by interoception, and this then permits the further transformation of the cellular arrays and morphological states, both of which drive forward the process of development. An open question is whether either of the approaches, LST or Lsystems, which have been employed in the study of information processing and transfer in relation to plant development, can be incorporated into Biosemiotics.

\section{References}

Alpi, A., Amrhein, N., Bertl, A., Blatt, M.R., Blumwald, E., Cervone, F., and 30 other authors (2007) Plant neurobiology: no brain, no gain? In: Trends in Plant Sciences, 12. pp 135-136.

Auden, W.H. (1948) The Age of Anxiety. London. Faber and Faber.

Backster, C. (2003) Primary Perception. Anza, CA. White Rose Millenium Press.

Baluška, F., Volkmann, D., Hlavacka, A., Mancuso, S., Barlow, P.W. (2006) Neurobiological view of plants and their body plan. In: Baluška, F., Mancuso, S., Volkmann, D. (Eds.) (2006) Communication in plants. Berlin. Springer. pp 19-35.

Baluška, F., Barlow, P.W., Volkmann, D., Mancuso, S. (2007) Gravity-related paradoxes in plants: Plant neurobiology provides the means for their resolution. In: Witzany, G. (Ed.) (2007) Proceedings of the $6^{\text {th }}$ Gathering in Biosemiotics, Salzburg, July 2006). Tartu. Umweb (in press).

Barlow, P.W. (1992) A flowchart of processes responsible for the gravitropism, nutation and other growth movements of roots. In: Naturwissenschaften, 79. pp 34-37.

Barlow, P.W. (1993) The response of roots and root systems to their environment - An interpretation derived from an analysis of the hierarchical organization of plant life. In: Environmental and Experimental Botany, 33. pp 1-10.

Barlow, P. W. (1999) Living plant systems: How robust are they in the absence of gravity? In: Advances in Space Research, 23/12. pp 1975-1986.

Barlow, P.W. (2005) From cambium to early cell differentiation within the secondary vascular system. In: Holbrook, N.M., Zwieniecki, M.A. (Eds.) (2005) Vascular Transport in Plants. Amsterdam. Elsevier/Academic Press. pp 279-306.

Barlow, P.W. (2006) Charles Darwin and the plant root apex: closing a gap in living systems theory as applied to plants. In: Baluška, F., Mancuso, S., Volkmann, D. (Eds.) (2006) Communication in plants. Berlin. Springer. pp 37-51.

Barlow, P.W. (2007) Plant neurobiology and Living Systems Theory. In: BioEssays (submitted).

Barlow, P.W., Lück, J. (2004a) Deterministic cellular descendance and its relationship to the branching of plant organ axes. In: Protoplasma, 224. pp 129-143.

Barlow, P.W., Lück, J. (2004b) Cell division systems that account for the various arrangements and types of differentiated cells within the secondary phloem of conifers. In: Plant Biosystems, 138. pp 1179-1202.

Barlow, P.W., Lück, J. (2005) Repetitive cellular patterns in the secondary phloem of conifer and dicot trees, and a hypothesis for their development. In: Plant Biosystems, 139. pp 164-179.

Barlow, P.W., Lück, J. (2006) Patterned cell development in the secondary phloem of dicotyledonous trees: a review and a hypothesis. In: Journal of Plant Research, 119. pp 271-291. 
Barlow, P.W., Lück, J. (2007a) Structuralism and semiosis: Highways for the symbolic representation of morphogenetic events in plants. In: Witzany, G. (Ed.) (2007) Proceedings of the $6^{\text {th }}$ Gathering in Biosemiotics, Salzburg, July 2006. Tartu. Umweb (in press).

Barlow, P.W., Lück, J. (2007a) Rhythmic plant morphogenesis: recurrent patterns of idioblast cell production. In: Russian Journal of Plant Physiology (submitted).

Barlow, P.W., Powers, S.J. (2005) Predicting the environmental thresholds for cambial and secondary vascular tissue development in stems of hybrid aspen. In: Annals of Forestry Science, 62. pp 565-573.

Barlow, P.W., Lück, H.B., Lück, J. (2001) The natural philosophy of plant form: cellular autoreproduction as a component of a structural explanation of plant form. In: Annals of Botany, 88. pp 1141-1152.

Barlow, P.W., Volkmann, D., Baluška, F. (2004a) Polarity in roots. In: Lindsey, K. (Ed.) (2004) Polarity in Plants. Oxford. Blackwells. pp 192-241.

Barlow, P.W., Lück, H.B., Lück, J. (2004b) Pathways towards the evolution of a quiescent centre in roots. In: Biologia (Bratislava), 59, supplement 13. pp 21-32.

Bertalanffy, L. von (1950) Outline of a general system theory. In: British Journal for the Philosophy of Science, 1. pp 134-165.

Brenner, E., Stahlberg, R., Mancuso, S., Vivanco, J., Baluška, F., Van Volkenburg, E. (2006) Plant neurobiology; an integrated view of plant signaling. In: Trends in Plant Sciences, 11. pp 413-419.

Bugnicourt, M. (1983) Embryogénie des Hypericum de France. In: Bulletin de la Société Botanique de France 130, Lettres Botaniques. pp 195-205.

Chan, A. (2005) Communication Technology: Main Arguments. http://www.gravity7.com/articles arguments.html

Darwin, C., assisted by Darwin, F. (1880) The Power of Movement in Plants. London. Murray.

Deutsch, J.S. (2004) Segments and parasegments in Arthropods: a functional perspective. In: BioEssays, 26. pp 1117-1125.

Gazzarrini, S., McCourt, P. (2003) Cross-talk in plant hormone signaling: what Arabidopsis mutants are telling us. In: Annals of Botany, 91. pp 605-612.

Gönczy, P., Hyman, A.A. (1996) Cortical domains and the mechanisms of asymmetric cell division. In: Trends in Cell Biochemistry, 6. pp 382-387.

Haberlandt, G. (1884) Physiologische Pflanzenanatomie. Leipzig. Englemann.

Hawkes, T. (1989) Structuralism and Semiotics. London. Routledge.

Highkin, H.R. (1958) Temperature-induced variability in peas. In: American Journal of Botany, 45. pp 628-631.

Highkin, H.R. (1960) The effect of constant temperature environments and of continuous light on growth and development of pea plants. In: Cold Spring Harbor Symposia on Quantitative Biology, 25. pp 231-238.

Hillman, W.S. (1956) Injury of tomato plants by continuous light and unfavorable photoperiodic cycles. In: American Journal of Botany, 43. pp 89-96.

Jackson, M.B., Barlow, P.W. (1981) Root geotropism and the role of growth regulators from the cap: a re-examination. In: Plant Cell and Environment, 4. pp 107-123.

Jürgens, G. (2003) Growing up green: cellular basis of plant development. In: Mechanisms of Development, 120. pp 1395-1406.

Kirby, S. (2001) Spontaneous evolution of linguistic structure - An iterated learning model of the emergence of regularity and irregularity. In: IEEE Transactions on Evolutionary Computation, Vol. 5. pp 102-110.

Kramer, E.M. (2001) A mathematical model of auxin-mediated radial growth in trees. In: Journal of Theoretical Biology, 208. pp 387397.

Lindenmayer, A. (1971) Developmental systems without cellular interactions, their languages and grammars. In: Journal of Theoretical Biology, 30. pp 455-484.

Lück, J., Lück, H.B. (1987) From OL and IL map systems to indeterminate and determinate growth in plant morphogenesis. In: Lecture Notes in Computer Science, 291. pp 393-410.

Lück, J., Lück, H.B. (2000) A classification of plant meristems based on cellworks (3D L-systems). The maintenance and complexity of their cellular patterns. In: Carbone, A., Gromov, M., Prusinkiewicz, P. (Eds.) (2000) Pattern Formation in Biology, Vision and Dynamics. Singapore. World Scientific. pp 199-216.

McKnight, T.D. (2004) Plant telomere biology. In: Plant Cell, 16. pp 794-803.

Miller, J.G. (1978) Living Systems. New York. McGraw-Hill.

Miller, J.G., Miller, J.L. (1982) The Earth as a system. Behavioral Science, 27. pp 303-322.

Miller, J.G., Miller, J.L. (1990) Introduction: The nature of living systems. In: Behavioral Science, 35. pp 157-163.

Miller, J.L., Miller, J.G. (1995) Greater than the sum of its parts III. Information processing subsystems. In: Behavioral Science, 40. pp 171-269.

Mohr, H., Schopfer, P. (1995) Plant Physiology. Berlin. Springer.

Morelli, R.A., Walde, R.E., Akstin, E., Schneider, C.W. (1991) L-system representation of speciation in the red algal genus Dipterosiphonia (Ceramiales, Rhodomelaceae). In: Journal of Theoretical Biology, 149. pp 453-465.

Nothnagel, E.A. (1997) Proteoglycans and related components in plant cells. In: International Review of Cytology, 174. pp 195-291.

Notov, A. (2005) Functional organization and individual development of modular objects. In: Wulfenia, 12. pp 65-85.

Novak, M.A., Krakauer, D.C. (1999) The evolution of language. In: Proceedings of the National Academy of Sciences, USA, 96. pp 8028-8033. 
Paquette, A.J., Benfey, P.N. (2001) Axis formation and polarity in plants. In: Current Opinion in Genetics \& Development, 11. pp 405409.

Pattee, H. (1969) How does a molecule become a message? In: Lang, A. (Ed.) (1969) Communication in Development. New York. Academic Press. pp 1-16.

Piaget, J. (1971) Structuralism. London. Routledge and Kegan Paul.

Pillitteri, L.J., Sloan, D.B., Bogenschutz, N.L., Torii, K.U. (2007) Termination of asymmetric cell division and differentiation of stomata. In: Nature, 445. pp 501-505.

Porter, R. (2000) Enlightenment. Britain and the Creation of the Modern World. London. Penguin Books.

Porterfield, D.M. (2002) Environmental sensing and directional growth of plant roots. In: Waisel, Y., Eshel, A., Kafkafi, U. (Eds.) (2002) Plant Roots. The Hidden Half. New York. Marcel Dekker. pp 471-487.

Sanders, W.B. (2006) A feeling for the superorganism: expression of plant form in the lichen thallus. In: Botanical Journal of the Linnean Society, 150. pp 89-99.

Silk, W.K., Erickson, R.O. (1978) Kinematics of hypocotyl curvature. In: American Journal of Botany, 65. pp 310-319.

Slack, J.M.W., Holland, P.W.H., Graham, C.F. (1993) The zootype and the polytypic stage. In: Nature, 361. pp 490-493.

Takahashi, N., Yamazaki, Y., Kobayashi, A., Higashitani, A., Takahashi H. (2003) Hydrotropism interacts with gravitropism by degrading amyloplasts in seedling roots of Arabidopsis and radish. In: Plant Physiology, 132. pp 805-810.

Valéry, P. (1919) The Crisis of the Mind. In: Lawler, J.R. (Ed.) (1977) Paul Valéry: An Anthology. Princeton. Princeton University Press.

van Fleet, D.S. (1948) Cortical patterns and gradients in vascular plants. In: American Journal of Botany, 35. pp 219-227.

Varela, F.J., Maturana, H.R., Uribe, R. (1974) Autopoiesis: The organization of living systems, its characterization and a model. In: Biosystems, 5. pp 187-196.

Wagner, G.P. (1996) Homologues, natural kinds and the evolution of modularity. In: American Zoologist, 36. pp 36-43.

Walbot, V. (1996) Sources and consequences of phenotypic and genotypic plasticity in flowering plants. In: Trends in Plant Sciences, 1. pp 27-32.

Walsingham, Lord John (2006) On the Origins of Speaking. Oxford. Trafford Publishing.

Went, F.W. (1956) The role of environment in plant growth. In: American Scientist, 44. pp 378-398.

White, L.L. (1944) The Next Development in Man. London. Cresset Press.

Witzany, G. (2006) The Logos of the Bios 1. Tartu. Umweb. 